\section{EMBRYRIDDLE}

Aeronautical University

SCHOLARLY COMMONS
Journal of Aviation/Aerospace

Education \& Research

Volume 3

Number 1 JAAER Fall 1992

Article 2

Fall 1992

\title{
A Turning Point in Aviation Training: The AQP Mandates Crew Resource Management and Line Operational Simulations
}

Thomas R. Weitzel

Henry R. Lehrer Ph.D.

Follow this and additional works at: https://commons.erau.edu/jaaer

\section{Scholarly Commons Citation}

Weitzel, T. R., \& Lehrer, H. R. (1992). A Turning Point in Aviation Training: The AQP Mandates Crew Resource Management and Line Operational Simulations. Journal of Aviation/Aerospace Education \& Research, 3(1). https://doi.org/10.15394/jaaer.1992.1081

This Article is brought to you for free and open access by the Journals at Scholarly Commons. It has been accepted for inclusion in Journal of Aviation/Aerospace Education \& Research by an authorized administrator of Scholarly Commons. For more information, please contact commons@erau.edu. 


\title{
A TURNING POINT IN AVIATION TRAINING: THE AQP MANDATES \\ CREW RESOURCE MANAGEMENT AND LINE OPERATIONAL SIMULATIONS
}

\author{
Thomas R. Weitzel and Henry R. Lehrer, Ph.D.
}

\begin{abstract}
Crew Resource Management (CRM) and Line Oriented Flight Training (LOFT) have not been mandatory elements of air carrier flight crew training. Additionally, Full-Flight Simulation and Flight Training Devices (FTDs) have been tools utilized to various degrees by the different air carrier training departments. Each air carrier's training program has traditionally been approved by its Federal Aviation Administration (FAA) Principal Operations Inspector (POI).

The Advanced Qualification Program (AQP) is an alternative method of training air carrier flight crewmembers and will be a voluntary program applicable to airline certificate holders under the Code of Federal Regulations Section 14 (14 CFR--encompasses aeronautics and space) Parts 121 and 135.

The FAA has facilitated the implementation of AQPs with the issuance of a Special Federal Aviation Regulation (SFAR 58), rather than rewriting the numerous Federal Aviation Regulations (FARs) which detail air carrier training. Additionally, an Air Carrier Training Branch (AFS-210) has been established to administer AQPs, with quality control being developed by a human factors specialist. Mandatory CRM training and the utilization of Line Operational Simulations (LOS--a rechristening of LOFT) are key elements of the AQP curriculum for flight crewmembers. As AQPs are approved, increased utilization of FTDs may augment and optimize Full-Flight Simulation. ". . . it is anticipated that AQP will become standard practice in the future for FAR Parts 121 and 135 operators" (Longridge and Boothe, 1991).
\end{abstract}

\section{BACKGROUND}

Two chilling statistics were raised early during the December 1990 Third Human Error Avoidance Techniques Conference at Dallas, Texas:

1. From 1980 to 1989 , over 72 percent of the world's airline hull losses were avoidably crew caused--only a slight improvement over the previous decade.

2. If the current rate stays absolutely flat, a projection based on the increase in the number of airplanes in service shows that, by the year 2005 , there will be an airline hull loss somewhere in the world approximately every two weeks. (Scahill, 1991, p. 43)

However, we have endured such losses for many years and, unfortunately, many of the loses were a result of human failing. Historically, the 1961 crash of a British aircraft in Norway was one of the first documented cases of a flight crew performance-related accident. Listed among the contributing factors of that accident were the added stress of a long delay prior to departure coupled with poor destination weather and:

the Viking used to fly with two pilots and a radio officer. There is a third seat for this third man in the cockpit. But then it became standard procedure to fly the Viking without the radio officer. He was regarded as redundant. A change in philosophy you know. Withoutsubstituting new mechanical aids, his absence meant extra workload for the pilots. They could cope with it, in normal circumstances. Others have been coping with it ever since. (Barlay, 1970, p. 12.) 
In another accident (NTSBAAR-80-5), among the factors contributing to the crash were inadequate company and crew management of resources; also cited were fatigue and individual high workload. Similarly, the 1982 Air Florida crash in Washington, DC during a blizzard (NTSB-AAR-82-8) had causal factors related to inappropriate crew decisions and inadequate company as well as FAA monitoring of crew training procedures.

In retrospect, there seems to be a common thread running through each of these accident reports. The thread is that seemingly well trained and highly motivated flight deck crews are making many incorrect and/or inappropriate decisions resulting in a preventable loss of life and property. To this end the FAA has recently taken positive and possibly far reaching steps toward developing new and more appropriate means of training certificated air carrier flight crews.

TRAINING FOR THE 1990s

FAR Parts $61,63,65,108$, 121 , and 135 contain regulations covering air carrier training programs. These parts designate training and qualification requirements, including applicable certification requirements, for airline operationspersonnel.Subparts $N$ and $O$ of FAR 121 contain the most detailed and rigorous training and qualification requirements. However, the last comprehensive changes to subparts $\mathrm{N}$ and $\mathrm{O}$ were made in 1970.

The FARs have focused on the training of individuals and have not referred to the training of crews. Consequently, crew concept training such as CRM and LOFT have been extracurricular in terms of the FARs. The FARs have tended to emphasize redundant checks of basic aircraft maneuvers; e.g., takeoffs, area departures, steep turns, and stalls.

Concurrently, Boeing (one of only three Western world manufacturers of large turbojet transports) has placed over 400 high-technology Boeing $757 \mathrm{~s}$ and $767 \mathrm{~s}$ into service with U.S. airlines. Cockpits in these aircraft have led their two-pilot crews to refer to the aircraft as "electric jets."

As pilots have moved into high-technology cockpits requiring new skills, they are finding that recurrent training to comply with regulations is akin to a professor reciting the alphabet to a government monitor every six months. (Ott, 1990, p. 68)

In August 1987, then FAA Administrator T. Allan McArtor urged the development of a joint government/ industry task force to study flight crew performance. Among other perceived problems on air carrier flight decks, the task force addressed flight crew training. The task force forwarded to FAA a series of recommendations to improve the flight crewmember operating environment, knowledge of human factors, and pilot training. The result has been SFAR 58, which outlines the steps an airline can take to establish its own AQP--an FAA-approved training program.

The AQP will be an alternative method for meeting training, evaluation, certification, and qualification requirements for the following: flight crewmembers (pilots and flight engineers), flight attendants, aircraft dispatchers, instructors, evaluators, and other operations personnel, e.g., aircraft mechanics. An objective of the $A Q P$ will be to enhance these professionals' qualifications above the standards of Parts 121 and 135. This article will encompass only Part 121 flight crewmember training.

Utilization of a systematic approach to training analysis, curriculum development, implementation, and evaluation will be fundamental to the AQP. Another fundamental underpinning of this program will be proficiencybased training and qualification. Time spent in AQP training will be quality, planned hours instead of programmed hours. Training will be conducted until the student flight crewmember successfuily completes the program.

All AQPs will require the incorporation of CRM and 
LOS in the curriculums. Accordingly, the AFS-210 has published FAA Advisory Circulars (ACs) 120-51 (1989) and 120-35B (1990b) covering, respectively, CRM training and evaluation and LOS training and evaluation. Additionally, the subjects of ACs 120-45A (1990a) and 120-40B (1991b) are, respectively, FTDs and Airplane Simulator Qualification. AC 120-54 (1991a) with the subject matter of the AQP has been published and will be discussed later in this article.

THE AQP

FUNDAMENTALS AND PERFORMANCE OBJECTIVES

The FAA has established AFS-210, which includes a human factors scientist on staff, in Washington, DC, to administer the $A Q P$ applications and operations. Air carriers will have to work with AFS.210 through a five-phase process to establish an AQP. The five phases, as defined by the FAA $(19 \times())$ in SFAR 58, are:

1. Phase One. The initial application by an air carrier states performance objectives and their planned implementation. At this point, an AFS-210 team will be assigned to the carrier.

2. Phase Two. The curriculum development, according to the Air Line Pilots Association (ALPA), is "the most important phasen (1990, April, p. 17). Analysis of training goals and objectives, incorporating task analyses and evaluation strategies, will result in written curriculum.

3. Phase Three. Implementation schedules and requirements will be produced, and instructors and evaluators will be trained.

4. Phase Four. Initial operations - will begin, and data will be collected to analyze the program.

5. Phase Five. If proceeding as planned, the operations will continue.

(A more detailed explanation exists within the 1990 SFAR

58.) The AFS-210 will assure that an approved AQP will:

1. Improve safety by training flight crewmembers to proficiency.

2. Incorporate CRM principles.

3. Employ LOS for training and evaluations.

4. Initiate or improve instructor and evaluator qualification programs.

5. Utilize a crew complement for training and qualification.

6. Utilize appropriate advanced training equipment.

The roles and responsibilities of the POIs will be to:

1. Involve themselves fully in air carriers' $A Q P$ reviews and evaluation processes.

2. Work with both applicant air carriers and the AFS210 during AQP applications.

3. Issue final approvals, in conjunction with the Manager of AFS-210, which per- mit continued operation of AQPs.

\section{CRM and LOS}

The National Aeronautics and Space Administration (NASA) review of air carrier accidents between 1968 and 1976 identified 62 accidents related to improper resource management. The cockpit skills identified with resource management included communication, leadership, planning, problem solving, and decision making (Sams, 1987).

During the mid-1980s, Helmreich (1984) began to clarify the much maligned term "pilot error." Helmreich and NASA research demonstrated that the majority of air carrier transport accidents were caused by failures in team communication and coordination.

Most of us are familiar with the common stereotype of the pilot as a fearless, self-sufficient, technically qualified, and slightly egotistical individual, whose job description calls for the defiance of death on a regular basis. (Foushee and Helmreich, 1988, p. 191).

Pilots with such traits were unlikely to function well in the multi-pilot crew when there was a need for teamwork and group decision making.

The FAA has allowed air carriers some latitude in developing their own unique approaches to CRM. This latitude may be attributable to a 
lack of a uniform, industrywide definition of how to approach such training. Specifically, the FAA (1989) has defined CRM with seven basic concepts and recommends four phases of teaching, while Sams (1987) listed numerous additional sources of CRM concepts and training strategies. Schwartz (1987), on the other hand, listed 10 topics associated with CRM which closely parallel the 14 CRM tools delineated (for statistical purposes) by Helmreich, Wilhelm, Gregorich, and Chidester (1990). Indeed, there have been many definitions of CRM.

Helmreich et al. (1990) reported the first data from the NASA/University of Texas Crew Performance project on the behavior of flightcrews with and without formal CRM. Fifteen rating areas of CRM included 14 areas of behavior (the tools) and the overall evaluation. Both LOFT scenarios and line operations were studied at two air carriers; one with CRM and LOFT already in place, and the other in early initiation of both. The results indicated that a formal CRM program resulted in an increased percentage of crews rated as above average in performance. There was also a decrease in the percentage rated as below average.

Classroom training of CRM has traditionally created a subset of flight crewmembers who react negatively (Helmreich and Wilhelm, 1989). The incorporation of crew as well as individual CRM evaluations in LOS scenarios is designed into the $A Q P$ to address this problem. The mandated combination of CRM and LOS evaluations has been designed to address communications in two-pilot crews. Kanki, Lozito, and Foushee (1989) concluded that standardization of communication patterns enhances the performance of the two-pilot crew; and Wiener (1989) addressed this problem specifically in the "glass cockpit" aircraft. The electric jets studied by Wiener pose problems at the human-automation interface. Incorporation of standard communications, and the appropriate separation of the human from the automation, will be quintessential to the CRM and LOS ingredients of an AQP designed to properly interface flight crewmembers and the airplanes they fly.

In discussing situational awareness, Schwartz (1987) stated that CRM skills are needed to:

1. Handle the increasing flow of information available from both inside and outside the cockpit.

2. Understand today's aircraft which, though increasingly automated, are often extremely complex.

3. Assure that flight crews perform as a coordinated team.
4. Fit into an evermore demanding ATCenvironment.

5. Integrate corporate pressures to go to new and different places.

6. Cope with changing skill and experience levels among associates.

7. Avoid complacency. ( $p$ 5)

Decision making involving good judgment is common to most definitions of CRM. Formal training or education in good pilot judgment has generally been considered as unattainable by the aviation community (Buch and Diehl, 1984). However, if a formal judgment matrix were designed, it must not conflict with any FAA legalities, approveci procedures, or checklists; or any of the air carrier's operational policies.

Line Operational Simulations (LOS) will utilize scenarios of operational problems and environmental conditions. LOS elements will be similar to those of LOFT: (a) a line environment; (b) a complete crew, with no substitution of instructors or evaluators; (c) random real world, real time scenarios; and (d) the option of runs which are uninterrupted. In addition, unlike LOFT, the simulations must include evaluation of each crewmember, crew competence, and crew performance (FAA, 1990b).

EVALUATIONS AND DATA

A sma!l, random sample of flight crewmembers would be among the first crews enrolled in an air carrier's early AQP. 
An audit and analysis of performances by this group would serve as a formative evaluation of the AQP courseware for technical accuracy, instructional soundness, and suitability for use. Additionally, simulator flight proficiency training will permit flight crewmembers to experience and practice events which are not normally encountered in day-to-day flight operations. The training to proficiency will necessitate the evaluation of crews and individuals. Results of data obtained from this process can be evaluated, possibly necessitating curriculum revisions.

Crew members will be provided with forms to evaluate the AQP. These evaluation forms will be comprised of several Likert scale questions, and questions or statements soliciting comments. Likert scales may be from "1" to "5", or "1" to "7"; the Likert extremes could be from: Unrealistic to Realistic; Easy to Difficult; Poor to Well; Useless to Useful; Absolutely nothing to $A$ tremendous amount; or Strongly disagree to Strongly agree.

Sample questions and statements soliciting comments are an important, integral part of the evaluation process. The CRM advisory circular 120-51 (1989) incorporates a sample student evaluation as well as other guidelines for student evaluations. For the AQP, sample questions could be:

1. Was the simulator a fair evaluation of your abilities as a crewmember?

2. Did the instructor provide the necessary guidance and techniques to improve proficiency in your crew position?

3. What did you find most useful in ground training?

4. What do you feel would improve the effectiveness of the AQP?

\section{FINANCIAL CONSIDERATIONS}

The FAA (1990c) has mentioned the AQP as possibly extending the time between crewmember visits to the training center as a financial consideration for air carriers. However, ALPA (1990) believes that the time between visits to the training center should not be extended beyond the annual recurrent and six-month proficiency checks that are now required. Ott (1990) mentioned that although the AQP was established in concert with the Air Transport Association, association members have expressed concern that additional training costs may be significant. Statistically, several years of AQP will be necessary to build a database for comparison to the accident history of the last 30 years.

The FAA utilized air carrier accident statistics for the past 20 years to arrive at a historical annual accident cost of approximately $\$ 66$ million for Part 121 and 135 operators. Projecting the accident rates for the next five years resulted in an average annual economic loss estimated to be \$145 million for Part 121 and 135 air carriers. The FAA projected an average annual cost savings of $\$ 70.8$ million for Part 121 and 135 operators, if all were to utilize the $A Q P$ for the next five years (1990c). The FAA also utilized a comparison of two AQP benefit-cost five year cases for Part 121 and 135 air carriers. In the first case, it was assumed $100 \%$ of the large Part 121 and Part 135 operators would participate in the $A Q P$ starting in the first year. It was also assumed that the AQP would be only $20 \%$ effective in the reduction of crew-caused accidents. A worst case scenario was considered for comparison. Only 5\% of the crews for the large Part 121 and Part 135 operators would participate in the AQP, and its effectiveness would be only $1 \%$ (1990c).

The first case resulted in a possible five-year savings to the industry of $\$ 443$ million (1990 dollars); costs were projected at $\$ 88$ million. The second case resulted in a fiveyear stream of benefits of $\$ 22$ million; costs were $\$ 10$ million. Both benefit ratios would be higher if the $A Q P$ were to be more than $20 \%$ effective in reducing crew-caused air carrier accidents (FAA, 1990c).

\section{CONCLUSIONS AND}

\section{RECOMMENDATIONS}

The AQP front-end curriculum development may also result in an initial analysis of 
training system devices and motion-based simulation. The consequence of such analysis may be the utilization of more FTDs in the curriculum. This utilization may also drive the FAA and/or NASA to further study motion-based simulation and its transfer of training to transport category aircraft operations. Experimental results of the transfer of training with motion-based simulation may end the question of duplicity which exists today with respect to air carrier simulation.

Other regions of the world are experiencing rates of crewcaused air carrier accidents greater than that of the U.S.; some of these geo-regional rates are in excess of six times greater than the U.S. rate. Given today's globalized society, future research should probably evaluate the human factors and crew training approaches for the air carriers of the following regions: Europe, Asia/Pacific, Latin America, and Africa/Middle East.

Perhaps there will be a true turning point in aviation training, but it is yet to be determined whether the certificated air carriers will readily embrace this new concept or whether the AQP will have the intended effect on aviation safety. There are several air lines that have already progressed to Phase 2 of the AQP. As of this date, United, Delta, and Northwest Airlines have reached this stage, and several additional major airlines and regionals are progressing with $\mathrm{AQP}$.

AC $120-54$ seems to be a landmark attempt at providing a framework for the industry and the FAA to work more closely in concert than ever before. If this joint association bears fruit, it may provide innovative ways to better prepare not only flight crewmembers but flight attendants, aircraft dispatchers, instructors, evaluators, and other operations personnel subject to the training and evaluations requirements of FAR parts 121 and 135. This enabling movement could serve as the catalyst to assist a flight crews to better work together. The time may finally be at hand when the manner in which the whole process of cockpit interaction and management of resources will be talked about less and acted upon more completely. The industry as well as the traveling public could all benefit; $A Q P$ may be a win-win situation for all.

Thomas R. Weitzel earned a Bachelor of Science in Metallurgical Engineering from Illinois Insititute of Technology, and a Master of Aeronautical Science, from Embry-Riddle Aeronautical University. Mr. Weitzel is a pilot of Trans World Airlines.

Henry R. Lehrer holds a B.S. in Education from Ohio University, an M.S. in Education from Kent State University, and a $\mathrm{Ph} . \mathrm{D}$. in Higher Education Administration from Bowling Green State University. A professor of Aeronautical Science at Embry-Riddle Aeronautical University, he has an extensive publishing and presenting record, and is editor of The Journal of Aviation/Aerospace Education and Research (JAAER).

\section{REFERENCES}

Air Line Pilots Association. (1990, April). Advanced qualification program. Air Line Pilot, pp. 16, 17. Barlay, S. (1970). The search for air safety. New York: William Morrow.

Buch, G., and Diehl, A. (1984). An investigation of the effectiveness of pilot judgement training. Human Factors, 26 , 557-564.

Federal Aviation Administration. (1989). Cockpit resource management training (Advisory Circular 120-51). Washington, DC: U.S. Government Printing Office. 
Federal Aviation Administration. (1990a). Airplane flight training device qualification (Advisory Circular 120-45A). Washington, DC: U.S. Government Printing Office.

Federal Aviation Administration. (1990b). Line operational simulations: Line-oriented flight training, special purpose operational training, and line operational flight evaluation (Advisory Circular 120-35B). Washington, DC: U.S. Government Printing Office.

Federal Aviation Administration. (1990c). Special Federal Aviation Regulation (SFAR) 58. Washington, DC: Federal Register.

Federal Aviation Administration. (1991a). Advanced qualification program (Advisory Circular 120-54). Washington, DC: U.S. Government Printing Office.

Federal Aviation Administration. (1991b). Airplane simulator qualification (Advisory Circular 120-40B). Washington, DC: U.S. Government Printing Office.

Foushee, C., \& Helmreich, R. L. (1988). Group interaction and flight crew performance. In E. L. Wiener \& D. C. Nagel (Eds.), Human factors in aviation (pp. 189-225). San Diego, CA: Academic Press.

Helmreich, R. L. (1984). Cockpit management attitudes. Human Factors, 583-589.

Helmreich, R. L., and Wilhelm, J. A. (1989, April). When training boomerangs: Negative outcomes associated with cockpit resource management programs. Paper presented at the fifth international symposium on aviation psychology, Columbus, $\mathrm{OH}$.

Helmreich, R. L., Wilhelm, J. A., Gregorich, S. E., \& Chidester, T. R. (1990). Preliminary results from the evaluation of cockpit resource management training: Performance ratings of flight crews. Aviation, Space, and Environmental Medicine, 61, 576-579.

Kanki, B. G., Lozito, B. A., \& Foushee, H. C. (1989). Communication indices of crew coordination. Aviation, Space, and Environmental Medicine, 56-60.

Longridge, T. M., \& Boothe, E. M. (1991, April). Training implications of the FAA's new advanced qualification program. Paper presented at the International Training Equipment Conference, Maastricht, the Netherlands.

National Transportation Safety Board. (1980). Aircraft accident report. Downeast Airlines, Inc. Dehavilland DHC-6-200, N68DE, Rockland, ME, May 30, 1979 (Report No. NTSB-AAR-80-5). Washington, DC: Author.

National Transportation Safety Board. (1982). Aircraft accident report. Air Florida, Inc. Boeing 737-222, N62AF, Washington National Airport, Washington, DC, January 13, 1982 (Report No. NTSB-AAR-82-8). Washington, DC: Author.

National Transportation Safety Board. (1987). Aircraft accident report. Midwest Express Airlines, Inc. DC-9-14, N100ME, General Billy Mitchell Field, Milwaukee, WI, September 6, 1985 (Report No. NTSB/AAR-87/01). Washington, DC: Author.

Ott, J. (1990, June 11). Pilot training program keyed to teams, aircraft. Aviation Week \& Space Technology, pp. 68, 69.

Sams, T. L. (1987). Cockpit resource management concepts and training strategies. Unpublished doctoral dissertation, East Texas State University, Commerce, TX.

Scahill, F. (1991). Training committee representatives attend international safety conference. The Lancet, $\underline{3}(2), 43-45$.

Schwartz, D. (1987, October). Training for situational awareness. Paper presented at the Flight Safety Foundation 40th International Air Safety Seminar, Tokyo.

Wiener, E. L. (1989). The human factors of advanced technology ("glass cockpit") transport aircraft, (NASA Contract Report 177528). Moffett Field, CA: NASA Ames Research Center. 